\title{
New Tests of the New-Keynesian Phillips Curve
}

\author{
Jeremy Rudd and Karl Whelan \\ Division of Research and Statistics \\ Federal Reserve Board *
}

June 26, 2001

\begin{abstract}
Is the observed correlation between current and lagged inflation a function of backward-looking inflation expectations, or do the lags in inflation regressions merely proxy for rational forward-looking expectations, as in the newKeynesian Phillips curve? Recent research has attempted to answer this question by using instrumental variables techniques to estimate "hybrid" specifications for inflation that allow for effects of lagged and future inflation. We show that these tests of forward-looking behavior have very low power against alternative, but non-nested, backward-looking specifications, and demonstrate that results previously interpreted as evidence for the new-Keynesian model are also consistent with a backward-looking Phillips curve. We develop alternative, more powerful tests, which find a very limited role for forward-looking expectations.
\end{abstract}

JEL classification code: E31

Keywords: Inflation, Phillips curve

\footnotetext{
${ }^{*}$ Correspondence: Jeremy Rudd, Federal Reserve Board, Mail Stop 80, 20th and C Streets NW, Washington, DC 20551; e-mail: jeremy.b.rudd@frb.gov; tel.: (202) 452-3780; fax: (202) 872-4927. We are grateful to David Bowman, Doug Elmendorf, Vincent Hogan, David Lebow, Jesper Lindé, Dan Sichel, and Jonathan Wright for helpful comments on an earlier draft of the paper. The views expressed in this paper are our own and do not necessarily reflect the views of the Board of Governors or the staff of the Federal Reserve System.
} 


\section{Introduction}

An important stylized fact in macroeconomics is that the U.S. inflation process is well described by the reduced-form Phillips curve

$$
\pi_{t}=\alpha(L) \pi_{t-1}+\gamma(L) x_{t}+u_{t}
$$

where inflation, $\pi_{t}$, is modelled as a function of its lags and a measure of excess demand $x_{t}$ (such as the output gap or the unemployment rate). Despite this equation's ability to characterize historical inflation behavior, there is no real consensus regarding its structural interpretation - in particular, the presence of lagged inflation has been interpreted in at least two very different ways. In the first, more traditional view, agents formulate their expectation of this period's inflation rate in a backward-looking manner, which causes past inflation rates to become directly incorporated into current wage and price contracts. Under this view, equation (1) is a structural relationship, with the lags of inflation proxying for $E_{t-1} \pi_{t}$.

An alternative, more modern interpretation comes from the rational expectations staggered-contracting models of Taylor (1980) and Calvo (1983). As shown by Roberts (1995), these models imply a so-called new-Keynesian Phillips curve in which current inflation incorporates a forward-looking component:

$$
\pi_{t}=\beta E_{t} \pi_{t+1}+\gamma x_{t} .
$$

This model provides a different interpretation of the reduced-form relationship between current and lagged values of inflation: Lagged inflation appears to matter only because it is correlated with the rational expectation of next period's inflation rate. Although superficially similar to the traditional Phillips curve, the new-Keynesian Phillips curve carries very different implications for such practical questions as the optimal conduct of monetary policy and the cost of disinflation.

Jordi Galí and Mark Gertler (1999) have recently attempted to distinguish between these two interpretations by estimating a "hybrid" specification of the form

$$
\pi_{t}=\omega^{f} E_{t} \pi_{t+1}+\omega^{b} \pi_{t-1}+\gamma x_{t} .
$$

This model can be re-written as

$$
\pi_{t}=\omega^{f} \pi_{t+1}+\omega^{b} \pi_{t-1}+\gamma x_{t}+\epsilon_{t+1},
$$


where $\pi_{t+1}$ is actual (realized) inflation at time $t+1$ and $\epsilon_{t+1}$ is an expectational error. ${ }^{1}$ Under rational expectations, this error should be unforecastable at time $t$, so $\omega^{f}$ can be consistently estimated using variables dated $t$ or earlier as instruments for $\pi_{t+1}$. Employing this technique, Galí and Gertler estimated $\omega^{f}$ to be significantly larger than $\omega^{b}$, and interpreted this result as implying that the pure new-Keynesian curve provides a good approximation to the true inflation process.

This paper presents a new approach to testing the new-Keynesian Phillips curve. We motivate the usefulness of the new tests by first documenting a potentially serious problem with Galí and Gertler's estimates, which is that small specification errors in equation (4) can cause their procedure to yield highly misleading results. In particular, high estimates of $\omega^{f}$ and low estimates of $\omega^{b}$ turn out to be fully consistent with the true model's being a purely backward-looking specification. Intuitively, this situation obtains when a variable $z_{t}$ that belongs in the true model for inflation is erroneously omitted from the test specification. In this case, the regression error in equation (4) is no longer a pure expectational error, because it also includes the influence of $z_{t}$ on inflation. Estimates of $\omega^{f}$ will therefore be biased upwards as long as $\pi_{t+1}$ and the variables used to instrument for it are both correlated with $z_{t}$. In practice, it turns out to be highly plausible that these conditions will be met, and that the magnitude of the bias will be large.

In light of this potential problem with tests based on estimation of equation (4), we develop an alternative testing procedure. Specifically, we focus on direct estimation of the new-Keynesian model's closed-form solution, which predicts that inflation should be determined by the expected present discounted sum of future values of the "driving" variable $x_{t}$ :

$$
\pi_{t}=\gamma \sum_{i=0}^{\infty} \beta^{i} E_{t} x_{t+i} .
$$

(This result is obtained from repeated substitution of equation 2.) We also present other tests that augment this specification with lags of inflation.

If Galí and Gertler's test equation is correctly specified, then the present-value tests that we construct are equivalent to their tests, and should yield similar results. However, our tests turn out to be far less likely to spuriously indicate the presence of forward-looking behavior when such behavior is not present. This is because in

\footnotetext{
${ }^{1}$ That is, $\epsilon_{t+1}$ is proportional to $\left(E_{t} \pi_{t+1}-\pi_{t+1}\right)$.
} 
this case, the term being instrumented for in the present-value test will not have a high correlation with variables that have been omitted from the inflation equation.

Our new tests strongly reject the new-Keynesian interpretation of the reducedform Phillips curve. The reason for this result is quite simple. From equation (5), we can see that if the new-Keynesian model were correct, then the lags of inflation that enter the reduced-form Phillips curve must be proxying for the rational expectation of future values of the driving variable $x_{t}$. However, our analysis rejects this conjecture. We show that lags of inflation actually have very little predictive power for future values of $x_{t}$, a result that we obtain whether we define $x_{t}$ to be the output gap (as is commonly done) or labor's share of income (as has been proposed by Galí and Gertler). Not surprisingly, then, we find that the estimated effects of lagged dependent variables in inflation regressions are very similar whether or not we include measures of the expected present value of the driving variable. A key point is that these results imply that the new-Keynesian model should not be viewed as supplying an alternative explanation for the empirical importance of lagged inflation in reduced-form inflation equations; rather, this stylized fact should be considered strong evidence against the new-Keynesian model.

We conclude from these results that Galí and Gertler's estimates are likely the result of model misspecification, and also that the new-Keynesian model provides a poor description of the U.S. inflation process.

\section{Assessing Previous Tests of the New-Keynesian Model}

In this section, we discuss the properties of instrumental variables (IV) estimates of equation (4). We begin by presenting a set of baseline results that, on the surface, appear to indicate that forward-looking behavior is an important component of the inflation process. We then demonstrate that these results could also be obtained even if the true process for inflation does not involve forward-looking behavior.

\subsection{Empirical Estimates of the Hybrid Equation}

As we noted above, so long as equation (3) is a true representation of the inflation process, then the only errors that will obtain from estimating equation (4) - in which realized $\pi_{t+1}$ is substituted for $E_{t} \pi_{t+1}$-will be (rational) expectational errors. In 
this case, any variable dated $t$ or earlier should be orthogonal to the regression model's error term, and therefore constitutes a valid instrument for $E_{t} \pi_{t+1}$.

Table 1 reports the results that we obtain from fitting several different versions of equation (4). Like Galí and Gertler, we estimate the equation with GMM, employing the same set of instruments that they did (namely, four lags of each of the following variables: price inflation, labor's share of income, the output gap, the spread between long and short interest rates, compensation inflation, and commodity price inflation). ${ }^{2}$ Coefficient standard errors are reported in parentheses in the table, and are estimated with a 12-lag Newey-West covariance matrix. Estimation is quarterly, and ranges from 1960:Q1 to 1997:Q4.

The four sets of results reported in Table 1 use two different measures of inflation and two different definitions of the driving variable $x_{t}$. The measures of inflation that we consider are the log-difference of the GDP chain price index and the log-difference of the chain price index for nonfarm business (NFB) output. The NFB deflator is our preferred price concept because it excludes prices for government and householdsector output and so is more likely to reflect the type of optimizing private-sector behavior that is posited by the sticky-price models that underlie the new-Keynesian model; we also report results for the GDP deflator to permit comparison with previous studies. The two measures of $x_{t}$ that we employ are the output gap (defined as the quadratically detrended log of real GDP) and the share of labor income in production costs for nonfarm business. The output gap is a standard activity variable that is commonly employed in Phillips curve regressions; however, Galí and Gertler have suggested the use of the labor income share, which can be equated with real marginal cost under certain restrictive assumptions. ${ }^{3}$

Because we estimate equation (4) directly, our approach differs a little in its particulars from Galí and Gertler's: They derive the new-Keynesian curve from a Calvo-style contracting model, and then use the estimated parameters from this model to back out estimates of $\omega^{f}, \omega^{b}$, and $\gamma$. Direct estimation has the advantage of

\footnotetext{
${ }^{2}$ We defined the long-short spread as the difference between the 10-year constant-maturity Treasury bond yield and the rate on three-month Treasury bills. Commodity price inflation was defined as the log difference of the Producer Price Index for crude materials.

${ }^{3}$ Specifically, we use the log of the ratio of the labor income share to its sample mean. This captures the notion that the driving variable should be expressed in terms of log deviations from its steady-state level.
} 
allowing easier interpretation in that the new-Keynesian Phillips curve is consistent with a broad class of sticky-price models. In practice, however, this choice has little substantive implication: When we implement Galí and Gertler's procedure, we obtain estimates for $\omega^{f}, \omega^{b}$, and $\gamma$ that are essentially identical to those that we report here.

Our estimates of the effects of the driving variables are a little different from Galí and Gertler's. Like them, we find that the coefficients on the output gap in this specification are insignificant and have the "wrong" sign. Unlike them, we do not find the labor income share to be statistically significant either, although it does have the correct (positive) sign. However, concerning the main point of interest - the relative sizes of $\omega^{f}$ and $\omega^{b}$ - the results in Table 1 are very similar to those obtained by Galí and Gertler. Specifically, we find estimates of $\omega^{f}$ that are much higher than those for $\omega^{b}$, particularly for our preferred price concept, the NFB deflator.

\subsection{The Effect of Misspecification on the Hybrid Model Estimates}

Taken at face value, the results in Table 1 suggest that the new-Keynesian conjecturethat the presence of lagged inflation in the reduced-form Phillips curve reflects its correlation with expected future inflation - is essentially correct, and that the pure new-Keynesian model with $\omega^{b}=0$ may be a good approximation to reality. This conclusion is reasonable as long as the test specification nests the true model. It turns out, however, that small misspecifications can result in highly misleading parameter estimates. We can demonstrate this as follows.

Assume that the true process for inflation is a backward-looking Phillips curve of the form

$$
\pi_{t}=\beta \pi_{t-1}+\lambda x_{t}+\mu z_{t}+u_{t},
$$

where $z_{t}$ denotes a vector of additional determinants of inflation. For simplicity, assume also that the $x_{t}$ and $z_{t}$ terms are defined such that $\lambda$ and $\mu$ are both positive (note that $\beta$ is invariably positive in Phillips curve specifications like this one).

Suppose now that we fit equation (4) using GMM, and that the instruments used to fit the model include $z_{t}$ - that is, variables that actually belong in the true model for inflation. Such a situation is quite plausible in this context. Recall that the instruments used by Galí and Gertler included additional lags of inflation and 
the output gap and lags of commodity price inflation - variables that are commonly employed in empirical inflation equations. ${ }^{4}$ However, beyond these specific variables, it seems generally likely that instrument selection for this equation will be highly problematic. A good instrument for this problem - in the sense that it allows $\omega^{f}$ to be identified - will be a variable that is correlated with the portion of $\pi_{t+1}$ that is orthogonal to $\pi_{t-1}$ and $x_{t}$. As a result, it is hard to think of a good instrument for $\pi_{t+1}$ (dated $t$ and earlier) that could not also plausibly be included in a model for $\pi_{t}{ }^{5}$

Because equation (4) is a linear model, the GMM procedure employed here is the same as two-stage least squares. ${ }^{6}$ Specifically, an equivalent estimation scheme begins by using the fitted values from a first-stage regression of $\pi_{t+1}$ on $\pi_{t-1}, x_{t}$, and $z_{t}$ in order to construct a proxy for expected future inflation. ${ }^{7}$ These fitted values $\hat{\pi}_{t+1}$, which can be written as

$$
\hat{\pi}_{t+1}=\hat{\delta}_{1} \pi_{t-1}+\hat{\delta}_{2} x_{t}+\hat{\delta}_{3} z_{t},
$$

are then used in a second-stage regression that relates current inflation to expected future inflation (proxied for by $\hat{\pi}_{t+1}$ ), lagged inflation, and a driving variable $x_{t}$ :

$$
\pi_{t}=\hat{\omega}^{f} \hat{\pi}_{t+1}+\hat{\omega}^{b} \pi_{t-1}+\hat{\gamma} x_{t}+\epsilon_{t} .
$$

Combining the first- and second-stage equations allows us to rewrite the hybrid model (8) as:

$$
\pi_{t}=\left(\hat{\omega}^{f} \hat{\delta}_{1}+\hat{\omega}^{b}\right) \pi_{t-1}+\left(\hat{\omega}^{f} \hat{\delta}_{2}+\hat{\gamma}\right) x_{t}+\hat{\omega}^{f} \hat{\delta}_{3} z_{t}+\epsilon_{t}
$$

If we compare equation (9) with the assumed true model (6), it is apparent that we can express the probability limits of the estimated parameters from the hybrid

\footnotetext{
${ }^{4}$ See Staiger, Stock, and Watson (1997) and Gordon (1998) for typical implementations.

${ }^{5}$ In theory, one might imagine that tests of overidentifying restrictions could be used to detect invalid instruments. However, as we discuss below, it is unlikely that these tests will actually be able to do so.

${ }^{6}$ See Hamilton (1994, pp 420-421) for a discussion.

${ }^{7}$ Note that the empirical estimates reported in the previous subsection were obtained using instruments dated time $t-1$ or earlier. (While it would have been valid to use time- $t$ variables as instruments, we employed the more restricted instrument set in order to match the procedure that Galí and Gertler followed in obtaining their results.) Here, we have assumed that the instrument set contains $x_{t}$ as well as elements of $z$ dated time $t$ or earlier; note that this is done merely to simplify the exposition, and makes no real difference to the argument.
} 
model in terms of the parameters of the true model:

$$
\begin{aligned}
\operatorname{plim}\left(\hat{\omega}^{b}+\hat{\omega}^{f} \hat{\delta}_{1}\right) & =\beta, \\
\operatorname{plim}\left(\hat{\gamma}+\hat{\omega}^{f} \hat{\delta}_{2}\right) & =\lambda, \\
\operatorname{plim} \hat{\omega}^{f} \hat{\delta}_{3} & =\mu .
\end{aligned}
$$

To determine the signs of the biases in the estimated coefficients, note that because inflation is highly autocorrelated, it is likely that the estimated effects on $\pi_{t+1}$ of lagged inflation, the driving variable $x_{t}$, and the $z_{t}$ terms will have the same signs as their respective effects on $\pi_{t}$. In other words, the coefficients $\hat{\delta}_{1}, \hat{\delta}_{2}$, and $\hat{\delta}_{3}$ from the first-stage regression will typically have the same (positive) sign as the coefficients $\beta, \lambda$, and $\mu$ from the true model. It is evident from equation (12), therefore, that in general the estimated coefficient $\hat{\omega}^{f}$ will be positive, even though the "true" model does not include a forward-looking component.

Note also that the estimated values of $\hat{\omega}^{b}$ and $\hat{\gamma}$ will be biased downward relative to the true coefficients on $\pi_{t-1}$ and $x_{t}$. Intuitively, the reason for this bias is that the influence of lagged inflation and the output gap on current inflation is already partly captured by $\hat{\pi}_{t+1}$. If this term receives a positive weight, then $\pi_{t-1}$ and $x_{t}$ will be crowded out of the second-stage regression. ${ }^{8}$

For simplicity, we have assumed here that the instruments for $\pi_{t+1}$ were identical to the $z_{t}$ terms that were erroneously omitted from the estimated model. However, it is easy to see that the same conclusions will hold if we use instruments that are merely correlated with $z_{t}$. Again, this is a plausible scenario: Even if we do not think that our instruments truly belong in the inflation specification, to be good instruments for this problem they will need to be correlated with the part of $\pi_{t+1}$ that is orthogonal to $\pi_{t-1}$ and $x_{t}$. Almost by definition, such variables are likely to be correlated with the omitted $z_{t}$.

An Analytical Example: The preceding argument establishes the direction of the biases that result from misspecification. It is also important to note that the magnitude of these biases may be large. For instance, consider the case in which the

\footnotetext{
${ }^{8}$ These results help to explain Roberts's (2001) finding that estimates from this equation are sensitive to the inclusion of lagged inflation in the instrument set. When this variable is excluded we have $\hat{\delta}_{1}=0$, so the estimated $\omega^{b}$ will not be biased down so much.
} 
true model for inflation is given by (6), and $x_{t}$ and $z_{t}$ follow $A R(1)$ processes with autoregressive parameters $\rho_{x}$ and $\rho_{z}$. We can then derive analytical expressions for the probability limits of the estimated parameters; as we demonstrate in an appendix, these are given by:

$$
\begin{aligned}
\operatorname{plim} \hat{\omega}^{f} & =\frac{1}{\beta+\rho_{z}}, \\
\operatorname{plim} \hat{\omega}^{b} & =\frac{\beta \rho_{z}}{\beta+\rho_{z}}, \\
\operatorname{plim} \hat{\gamma} & =\lambda\left(\frac{\rho_{z}-\rho_{x}}{\beta+\rho_{z}}\right) .
\end{aligned}
$$

These results imply that plausible degrees of persistence in $x_{t}, z_{t}$, and $\pi_{t}$ can yield estimates of $\omega^{f}$ that are large relative to those for $\omega^{b}$, even when inflation is truly characterized by the backward-looking model (6). For example, if $\rho_{z}=\rho_{x}=$ $\beta=0.8$, then the probability limits for the estimated parameters are $\hat{\omega}^{f}=0.625$, $\hat{\omega}^{b}=0.4$, and $\hat{\gamma}=0$-results that are quite similar to those reported in Table 1 (and in Galí and Gertler's paper). ${ }^{9}$ It is particularly interesting to note that small or negative estimated coefficients on the driving variable, $x_{t}$-such as we found for the output gap - could be obtained even if this variable has a large positive effect in the true model.

Tests of Overidentifying Restrictions: As we have described it, the problem with testing equation (4) is one of potential model misspecification - we may have omitted variables from the estimated model that belong in the correct specification, and then compounded this error by using these omitted variables (or variables that are correlated with them) as instruments. In principle, one might hope that the Hansen (1982) test of the model's overidentifying restrictions could reveal the presence of this problem (note that for the models estimated in Table 1, this test does not reject the overidentifying restrictions). However, it is well known that this test tends to have low power; hence, at best the results from this test can provide only

\footnotetext{
${ }^{9}$ We used monte carlo simulations to confirm that for the sample sizes used in this paper, empirical estimates of the parameters will tend on average to be close to the analytical probability limits just derived. We also used monte carlo exercises to confirm that we obtain similar results when we employ a model for $\pi_{t}$ and higher-order $A R$ processes for $x_{t}$ and $z_{t}$ that are calibrated from the data.
} 
limited evidence against misspecification. ${ }^{10}$ In fact, beyond this general problem, it turns out that the test will be particularly ineffective in detecting the type of misspecification that we are considering.

To see this, note that for linear models the Hansen test is based on the size of the $R^{2}$ from a regression of the model's residuals (which in this case are equal to $\left.\pi_{t}-\hat{\omega}^{f} \pi_{t+1}-\hat{\omega}^{b} \pi_{t-1}-\hat{\gamma} x_{t}\right)$ on the instrument set. ${ }^{11}$ If the $R^{2}$ is "too high," then this is interpreted as evidence that the instruments are invalid. Here, however, the effect of the variables that are omitted from the estimated model are captured indirectly through the $\pi_{t+1}$ term. Since the manner in which these variables explain $\pi_{t+1}$ is likely to be similar to how they explain $\pi_{t}$, much of their influence on $\pi_{t}$ will actually be incorporated in the estimated specification. As a result, in this case the model will typically "pass" a Hansen test.

We have confirmed using monte carlo exercises that tests of the overidentifying restrictions invariably fail to detect the presence of this type of misspecification. Furthermore, in the appendix we show that for the example just discussed in which $x$ and $z$ are $A R(1)$, the $R^{2}$ underlying the Hansen test statistic should asymptotically tend toward zero, even though the model is misspecified by construction.

Summary: The results of this section demonstrate that instrumental variables estimation of equation (4) cannot provide convincing evidence that inflation expectations are forward-looking in nature. Our results thus far do not preclude the possibility that the $\hat{\pi}_{t+1}$ series is indeed a good proxy for agents' rational expectations of future inflation, and therefore that the high value of $\omega^{f}$ reported by Galí and Gertler (and in our Table 1) truly reflects the important role played by such expectations in the inflation process. However, they do imply that these results are also perfectly consistent with the traditional, backward-looking interpretation of the Phillips curve, and therefore that it is impossible to use this test to distinguish this theory of inflation dynamics from one based on backward-looking behavior. ${ }^{12}$

\footnotetext{
${ }^{10}$ Newey (1985) presents general results regarding the power of the Hansen test.

${ }^{11}$ This was noted by Newey (1985), who based his argument on an earlier result by Hausman (1984, pp 432-33).

${ }^{12}$ While we have focused on the problems related to instrumental variables estimation of equation (3), we should note that the issues highlighted here also apply to another popular method for estimating this equation, in which a survey measure is used as a proxy for $E_{t} \pi_{t+1}$ (see, for example,
} 


\section{Tests Based on the Closed-Form Solution}

In this section, we develop new tests that permit us to discriminate between the competing interpretations of the correlations summarized by the reduced-form Phillips curve. These tests achieve this goal by focusing more precisely on how inflation expectations are determined in the new-Keynesian model.

\subsection{The Closed-Form Inflation Equation}

Consider again the new-Keynesian Phillips curve in its simplest form (equation 2, reproduced here):

$$
\pi_{t}=\beta E_{t} \pi_{t+1}+\gamma x_{t} .
$$

The tests that we have discussed thus far have characterized this model based only on a very weak property of rational expectations - specifically, that the expectational error $\left(\pi_{t+1}-E_{t} \pi_{t+1}\right)$ should be unforecastable by variables dated $t$ or earlier. However, another feature of rational expectations is that they should be modelconsistent: Expectations for next period's inflation rate should be consistent with the process for inflation as described by the model. This additional prediction yields testable implications beyond those that we have already considered. More importantly for our purposes, it turns out that tests of these implications are much less likely to mislead when the type of misspecification that we discussed above is present.

Our new tests are derived from the following observation. If the new-Keynesian model is correct, then rational agents know that

$$
\begin{aligned}
& E_{t} \pi_{t+1}=\beta E_{t} \pi_{t+2}+\gamma E_{t} x_{t+1}, \\
& E_{t} \pi_{t+2}=\beta E_{t} \pi_{t+3}+\gamma E_{t} x_{t+2},
\end{aligned}
$$

and so on. Repeated substitution of these and higher terms yields the following closed-form solution for current inflation:

$$
\pi_{t}=\gamma \sum_{i=0}^{\infty} \beta^{i} E_{t} x_{t+i} .
$$

Roberts, 1995). Suppose that inflation were influenced by a variable $z$ that was observed by private agents but not included in the estimated model. In this case, a survey measure of expected inflation would receive a large weight in equation (3) even if the new-Keynesian model were false. 
Our strategy is to test whether (16) provides a good characterization of the inflation process. If it does, then this would confirm that the lags of inflation in reduced-form Phillips curves are merely proxying for forward-looking expectations. In addition to estimating (16), we also estimate specifications of the form

$$
\pi_{t}=A(L) \pi_{t-1}+\gamma \sum_{i=0}^{\infty} \beta^{i} E_{t} x_{t+i}
$$

This can be interpreted as combining elements of both the new-Keynesian Phillips curve and the traditional backward-looking model; alternatively, it can be explicitly derived from a modified staggered-pricing model in which the economy includes both forward- and backward-looking agents. ${ }^{13}$ Whichever interpretation one wants to give this equation, if the pure new-Keynesian model is a good proxy for the empirical inflation process, then we should obtain relatively small coefficients on lagged inflation.

When comparing the present-value tests with those reported in the previous section, the first thing to note is that, if the results in Table 1 are to be interpreted as indicating an important role for forward-looking behavior (as opposed to model misspecification), then these tests should yield equivalent results. If the new-Keynesian model is correct, then the forward-looking behavior that showed up in the previous tests as a large coefficient on the proxy for $E_{t} \pi_{t+1}$ should show up here in the form of a significant role for the present-value term. The only case in which this would not obtain would be if we had a poor proxy for the present-value variable; in the context of our estimation procedure, this would reflect the presence of a weak-instrument problem. However, as we will show below, the instruments for the present-value term have good first-stage fit. Thus, if we fail to find a significant role for forward-looking behavior with this test, then we can reject the pure new-Keynesian model as a good approximation to reality.

The second important aspect of these tests is that they provide a check on whether the results in Table 1 are due to the omission of one or more variables from the true model for inflation. When such variables are omitted, the presentvalue tests will not suggest forward-looking behavior if the true model is purely

\footnotetext{
${ }^{13}$ See Galí and Gertler (1999) for an example. (Note that in this case $\beta$ in equation 17 represents the inverse of the unstable root of the expectational difference equation implied by the hybrid model.)
} 
backward looking. To see this, note that unlike the previous tests - in which we were instrumenting for $\pi_{t+1}$-we have no a priori reason to expect that variables omitted from the inflation equation will be highly correlated with the present-value term that we are instrumenting for here. The explanation is simple: If the newKeynesian model is wrong, then the relationship between the present-value term and the instruments should be quite different from the relationship between inflation and the instruments. Thus, even if we have omitted some variables that are useful for explaining inflation, this test will not automatically conclude that there is forwardlooking behavior if none actually exists.

\subsection{Empirical Results}

Implementing the Model: To make equations (16) and (17) empirically tractable, we need to be able to construct a proxy for the infinite discounted sum of the expected future values of the driving variable. We do this by making use of the fact that

$$
E_{t} \pi_{t+K+1}=\gamma \beta^{-(K+1)} \sum_{i=K+1}^{\infty} \beta^{i} E_{t} x_{t+i},
$$

which allows us to truncate the infinite sum in equation (16) in some period $t+K$, and write the closed-form solution for inflation in terms of $K+1$ current and future values of the driving variable and a terminal inflation term:

$$
\pi_{t}=\gamma E_{t} \sum_{i=0}^{K} \beta^{i} x_{t+i}+E_{t} \beta^{K+1} \pi_{t+K+1} .
$$

Similarly, we can make equation (17) tractable by noting that

$$
E_{t} \pi_{t+K+1}=A(L) E_{t} \pi_{t+K}+\gamma \beta^{-(K+1)} \sum_{i=K+1}^{\infty} \beta^{i} E_{t} x_{t+i},
$$

which allows us to rewrite the closed-form solution for inflation as:

$$
\pi_{t}=A(L) \pi_{t-1}+\gamma E_{t} \sum_{i=0}^{K} \beta^{i} x_{t+i}+E_{t} \beta^{K+1}\left[\pi_{t+K+1}-A(L) \pi_{t+K}\right] .
$$

Given a value for $\beta$, we can construct the actual (realized) values of $\sum_{i=0}^{K} \beta^{i} x_{t+i}$ and the terminal inflation components. Again, if the new-Keynesian model is correct, then these terms will equal their time- $t$ expectations together with an unforecastable 
(rational) expectational error. Thus, we can also estimate equations (18) and (19) using instrumental variables techniques.

For the results that we discuss, we used GMM to estimate $\gamma$ based on an assumed value of 0.95 for $\beta$ and a value for $K$ of 12 quarters. We also examined a number of alternative values for $\beta$ ranging from 0.80 to 0.99 , as well as values for $K$ that range from eight to twenty quarters; the results were essentially the same as those described here. ${ }^{14}$ Because our dataset ends in 2000:Q2 and we require data for twelve quarters after the end of the estimation period, we estimate the model through 1997:Q2. The instrument set is the same as that employed in the previous tests. As before, we considered versions of the model that use either the GDP gap or the labor-income share as a driving variable, and that define inflation as the rate of change of either NFB or total GDP prices.

Estimates: Table 2 summarizes the results obtained from fitting equations (18) and (19). As a way of quantifying the new-Keynesian model's ability to explain the data, we also report results from simple regressions of inflation on its own lags only. ${ }^{15}$ If the new-Keynesian interpretation of the reduced-form Phillips curve is correct, then the inclusion of the present-value term should result in a substantial reduction in the coefficients on lagged inflation relative to those obtained from the purely backward-looking specifications.

Taken together, the results provide little support for the view that forwardlooking behavior is an important determinant of inflation dynamics. Beginning with the specification that uses the output gap as the driving variable, we see that $\gamma$ (the coefficient on the present-value term) does not even receive the correct sign in the version of the model that excludes any lags of inflation. When we incorporate the lagged inflation term $A(L) \pi_{t-1}$, we obtain further evidence that the forward-looking behavior posited by the new-Keynesian Phillips curve is of limited empirical importance: Although $\gamma$ receives the correct (positive) sign in

\footnotetext{
${ }^{14}$ For reference, Galí and Gertler's empirical estimates of $\beta$ range from around 0.93 for GDP price inflation to around 0.97 for NFB inflation.

${ }^{15}$ Our specific implementation of equation (19) has two lags of inflation (the results are essentially the same if we include additional lags). Similarly, the "own lags only" estimates reported in the table are from models that include two lags of inflation; the results are basically unchanged if we include additional lags, or additional driving variables such as the output gap.
} 
these specifications, the sum of the coefficients on lagged inflation (labelled " $A(1)$ " in the table) is about 0.9 for both GDP and NFB price inflation. And, in both cases, these estimates are virtually identical to the coefficients on lagged inflation from the autoregressions. Thus, we find essentially no evidence that the role assigned to lags of inflation in reduced-form Phillips curves comes from their proxying for expected future output gaps, as the new-Keynesian model suggests.

What about the version of the model that uses the labor income share as the driving variable? The pure new-Keynesian specification with this driving variable does a bit better inasmuch as the coefficient on the present-value term receives the correct sign. Nevertheless, even when we include this present-value term, the resulting weight given to lagged inflation remains very high, at about 0.8 for both GDP and NFB price inflation. These estimates are only a little lower than the 0.9 obtained for the pure autoregressive model, suggesting a very limited role for expected future values of the labor share.

These results yield a picture of the merits of the new-Keynesian model that is starkly different from the one presented by Galí and Gertler. While they argued that "[b]ackward-looking price-setting, while statistically significant, is not quantitatively important," and concluded that "the new-Keynesian Phillips curve provides a good first approximation to the dynamics of inflation," our results imply that as a first-order approximation to the inflation process, the model appears to fall well short of the mark. Moreover, expectations of future output gaps or labor shares appear to play a very small role in explaining why we find such large coefficients on lagged inflation in empirical Phillips curves.

\subsection{Why Does the New-Keynesian Model Fail?}

The empirical estimates from the preceding subsection suggest that forward-looking behavior plays little or no role in price setting. In this subsection, we explore exactly why it is that the new-Keynesian model fails to provide an adequate characterization of the inflation process.

The Role of Lagged Inflation: The new-Keynesian interpretation of the reducedform Phillips curve (equation 1) is that lags of inflation are given a significant weight in the regression only because they contain information about future values of the 
driving variable. Indeed, if one accepts this interpretation, then this informational content must be the reason that lags of inflation receive such a significant weight in the construction of the empirical proxy for $E_{t} \pi_{t+1}$ used in the regressions in Table 1. However, the reason the new-Keynesian model fails the present-value tests is that, as an empirical matter, this interpretation appears to be invalid.

To illustrate this point, Table 3 summarizes the coefficients that we obtained from regressions of the present-value term $\sum_{i=0}^{K} \beta^{i} x_{t+i}$ on lagged inflation, lags of the driving variable, and the other members of the instrument set used in estimating the models of the preceding subsection. (Note that the estimates using the full instrument set correspond exactly to the first-stage regressions from the IV estimates of the present-value specifications; as we claimed earlier, the first-stage fit for the present-value term is quite good.)

The key result from Table 3 is that lags of inflation contain very little predictive power for the present value of the driving variable. For the output gap, lagged inflation receives the "wrong" (negative) sign; moreover, excluding it from the specification has very little effect on the regression's fit. For the labor-income share, lagged inflation receives the correct sign, but once again has almost no marginal predictive power for the present-value term. Hence, the level of current inflation does not appear to provide a strong signal of future values of the output gap or labor's share.

The fact that inflation is not a positive leading indicator for the output gap (and the problem this causes for formulations of the new-Keynesian Phillips curve that use the output gap as a driving variable) was noted by Galí and Gertler. ${ }^{16}$ They also pointed out that inflation tends to be positively correlated with future values of the labor income share, and cited this as evidence supporting their choice of the labor share as a driving variable.

As far as the sign of this relationship is concerned, this pattern is also apparent in Table 3. However, our results also show that-once one looks beyond bivariate correlations - the relationship between inflation and future values of the labor share is a weak one. Indeed, with the full set of instruments, lagged inflation does not have a statistically significant effect on the present value of future labor shares. This explains why the empirical models of the previous section assigned a large weight to

\footnotetext{
${ }^{16}$ See pages $201-202$.
} 
lagged inflation even after this present-value term was included as an explanatory variable. And, it explains why the large estimated weight on lagged inflation found in reduced-form Phillips curves cannot be interpreted as resulting from its role as a proxy for the rational expectation of future labor shares.

The Role of Lagged $x_{t}$ : A notable feature of the results in Table 3 is that the lags of $x_{t}$ are by far the most important explanatory variables for the present value (this is particularly true for the output gap). This stems from the fact that both the output gap and labor share can be well-approximated as univariate autoregressive processes; in particular, for either series, the addition of lags of inflation (of any length) adds little explanatory power.

These univariate approximations can be used to illustrate exactly why the newKeynesian model cannot characterize inflation very well. Begin by noting that if a stationary variable $w_{t}$ is expressible as a univariate $A R(p)$ process

$$
w_{t}=\theta_{1} w_{t-1}+\theta_{2} w_{t-2}+\cdots+\theta_{p} w_{t-p}+\epsilon_{t}=\theta(L) w_{t-1}+\epsilon_{t},
$$

then we can use a formula of Hansen and Sargent (1980) to express the time- $t$ expectation of its present discounted value as

$$
\sum_{i=0}^{\infty} \beta^{i} E_{t} w_{t+i}=\alpha(L) w_{t}
$$

where

$$
\alpha(L)=\frac{1}{1-\theta(\beta)}\left[1+\sum_{k=1}^{p-1}\left(\sum_{r=k+1}^{p} \beta^{r-k} \theta_{r}\right) L^{k}\right]
$$

Hence, if the new-Keynesian model is correct, then the model's closed-form solution for current inflation can be well approximated as:

$$
\pi_{t}=\gamma \alpha(L) x_{t}
$$

It should be obvious, however, that this will provide a very incomplete characterization of inflation dynamics - it is basically just the reduced-form Phillips curve (1) without any lagged inflation terms. Indeed, Table 4 shows that empirical versions of equation (20) do very poorly no matter what definition of $x_{t}$ we use; in particular, adding $\alpha(L) x_{t}$ to an inflation autoregression barely changes the weight that 
lagged inflation receives in the model. In essence, this is another way of stating the point made above - namely, that the rational expectation of $E_{t} \pi_{t+1}$ implied by the new-Keynesian model cannot, in practice, explain more than a small fraction of the variation in current inflation.

In connection with this point, it is useful to consider a result reported by Galí and Gertler in their paper; namely, that a calculated series of the same form as the right-hand side of equation (17), calibrated using their preferred parameter estimates and a VAR to generate the $E_{t} x_{t+i}$ values, appeared to provide a reasonable fit to the inflation data. ${ }^{17}$ However, while Galí and Gertler's calibration exercise used the estimates from their GMM equations, our estimation procedure is designed to find the best-fitting version of equation (17). And the best-fitting estimates (the coefficients reported in Tables 2 and 4) have a substantially different economic interpretation, because they assign little importance to the expected future values of the driving variable.

Comparison with Fuhrer's (1997) Results: Our results provide a useful interpretation of Fuhrer's (1997) estimates, which indicated that forward-looking behavior is a relatively unimportant component of the inflation process. Fuhrer used numerical methods to estimate a version of equation (3) under the assumption that the driving term $x_{t}$ (in his work, the output gap) was a function of its own lags, lagged inflation, and lags of the Federal funds rate. Like the Hansen-Sargent approximation that we have just presented, this procedure essentially amounts to computing the expected present value of the driving variable under the assumption that $x_{t}$ follows a specific process, and then determining what fraction of inflation is accounted for by this present-value term. If the present value is well characterized as a function of lags of the driving variable (as the first-stage regressions in Table 3 suggest) then this method will be equivalent to the Hansen-Sargent formulation summarized by (20). Thus, though the empirical methodology of our IV-based tests of the forward-looking model is quite different from Fuhrer's in that it does not rely on specifying an explicit process for the driving variable, we believe that the same features of the data that cause us to reject the new-Keynesian curve are also behind Fuhrer's very similar conclusion.

\footnotetext{
${ }^{17}$ Galí and Gertler called this series "fundamental inflation" and illustrated it in Figure 2 of their paper.
} 


\subsection{Robustness of the Results from the Present-Value Tests}

We believe that the present-value tests provide convincing evidence that the newKeynesian Phillips curve cannot serve as an adequate approximation to the empirical inflation process. We have, however, shown that despite the poor fit of the newKeynesian model, empirical estimation of the hybrid equation (4) may still assign a high coefficient to future inflation if some variables that belong in the true model for inflation are used as instruments for $\pi_{t+1}$. In addition, we have shown how the present-value test procedures can still recover the correct answer - that the newKeynesian curve is a poor model - even if some of the instruments in this exercise belong in the true model for inflation.

At this point, a reasonable question to ask is whether the estimated coefficients from the present-value regressions (reported in Table 2) are affected by including some of the instruments in the estimation equation. This question is irrelevant for the key issue addressed in this paper; namely, whether the new-Keynesian model, with the output gap or labor share serving as the driving variable, explains the correlations described by reduced-form inflation regressions (clearly, neither version does). However, one may wonder whether our estimated coefficients on lagged inflation could be significantly biased by using as instruments variables that actually belong in the estimated model.

To address this issue, Table 5 reports the sum of the coefficients on the lagged inflation terms (the $A(1)$ values) from regressions that augment the specification estimated in Table 2 with each of our instruments (with the exception of the lagged values of $x_{t}$ ). In other words, these regressions add four lags of compensation inflation, commodity price inflation, and the spread between long- and short-term interest rates, as well as four lags of the labor share (for the equation using the output gap as the driving variable) and four lags of the output gap (for the equation using labor share as the driving variable).

As expected, these additional explanatory variables often receive statistically significant coefficients; nevertheless, the results do not change our main conclusions. The estimated $A(1)$ values from these regressions are a bit smaller than those reported in Table 2. However, they are still quite large - in the 0.6 to 0.75 range - and most of the reduction comes from including lags of compensation inflation (a variable that is highly correlated with price inflation) in the model. Moreover, we still 
obtain similar estimates of $A(1)$ whether or not we include present-value terms. ${ }^{18}$

These results tend to confirm our suspicion that some of the instruments used by Galí and Gertler likely belong in a well-specified empirical inflation regression. Futhermore, they provide additional confirmation for our conclusion that the significant role played by lags of inflation in reduced-form Phillips curves cannot be assigned to their proxying for expected present values of the output gap or the labor share of income.

\section{Concluding Comments}

The goal of this paper has been to assess whether the new-Keynesian Phillips curve can account for the empirical correlations that are summarized by reduced-form inflation regressions. We have concluded that it cannot. Specifically, we have focused on the new-Keynesian model's prediction that inflation should be a function of an expected present discounted value of some "driving variable" $x_{t}$ that summarizes excess demand or marginal costs. We have found that such present-value terms can explain only a very small fraction of observed inflation dynamics, a conclusion that we obtain whether we use the output gap or the labor income share as the driving variable. In addition, the idea that the important role assigned to lags of inflation by reduced-form Phillips curves comes from their proxying for expected future values of $x_{t}$ is contradicted by the minor role that inflation plays in forecasting future values of the labor share or output gap.

Our results yield an assessment of the new-Keynesian Phillips curve that is very different from the one found in Galí and Gertler's recent work. We believe the reason for this difference comes from the fact that their tests of the model have very low power against alternative, but non-nested, backward-looking specifications. In connection with this point, we have shown that Galí and Gertler's estimation procedure is likely to suggest that forward-looking behavior is very important even if the true model contains no such behavior.

We suspect that the conclusions of this paper will be unsurprising to some students of the staggered-contracting literature. Indeed, we view our results as com-

\footnotetext{
${ }^{18}$ Note that these regressions achieve identification of the coefficient on the expected present value solely through the lags of $x_{t}$ in the instrument set. As can be seen from Table 3, this avoids any problems associated with weak instruments.
} 
pletely consistent with Fuhrer and Moore's (1995) claim that the type of staggeredcontracting model from which the new-Keynesian Phillips curve is derived cannot deliver the degree of inflation persistence that we actually observe in the data. This problem is clearly evident in our own characterization of the model.

The results in this paper also provide a clear warning against the use of the newKeynesian Phillips curve (or hybrid variants that place a large weight on forwardlooking expectations) for policy analysis. The understandable appeal of these specifications, which allow nominal disturbances to have real economic effects in the context of a rational-expectations framework, has made them the model of choice for modern theoretical examinations of the optimal conduct of monetary policy. However, the implications of these models are not innocuous - for example, the fact that they imply that current inflation summarizes the entire sequence of expected future output gaps for the economy is an extremely strong prediction that may well influence one's assessment of the optimal choice of policy target (among other things). Given that this prediction is soundly rejected by the data, the use of these models for policy analysis strikes us as questionable at best.

We conclude by noting that, despite our finding that the new-Keynesian Phillips curve cannot explain the role played by lagged dependent variables in inflation regressions, our results should not necessarily be interpreted as implying that agents formulate expectations in a backward-looking manner, as in the traditional interpretation of the Phillips curve. We can think of two avenues through which future research may reconcile empirical inflation dynamics with rational behavior. First, it is possible that the important role assigned to lags of inflation could come from their proxying for expectations of some other driving variable that we have not considered. (That said, however, we hope that we have at least demonstrated that any future candidate driving variable should be tested in the context of the forwardlooking model's closed-form solution.) Second, it may be that the research agenda on inflation dynamics needs to move away from the sticky-price models that underlie the new-Keynesian Phillips curve, and towards other mechanisms that can generate the degree - and type - of inflation persistence that we observe in the data. Recent work by Sims (1998) and Mankiw and Reis (2001) represents two promising efforts in this direction. 


\section{References}

[1] Calvo, Gulliermo A. (1983). "Staggered Prices in a Utility Maximizing Framework," Journal of Monetary Economics, 12, 383-398.

[2] Fuhrer, Jeffrey C. (1997). "The (Un)Importance of Forward-Looking Behavior in Price Specifications," Journal of Money, Credit, and Banking, 29, 338-350.

[3] Fuhrer, Jeffrey C. and George Moore (1995). "Inflation Persistence," Quarterly Journal of Economics, 440, 127-159.

[4] Galí, Jordi and Mark Gertler (1999). "Inflation Dynamics: A Structural Econometric Analysis," Journal of Monetary Economics, 44, 195-222.

[5] Gordon, Robert J. (1998). "Foundations of the Goldilocks Economy: Supply Shocks and the Time-Varying NAIRU," Brookings Papers on Economic Activity, 297-346.

[6] Hamilton, James D. (1994). Time Series Analysis. Princeton, NJ: Princeton University Press.

[7] Hansen, Lars Peter and Thomas J. Sargent (1980). "Formulating and Estimating Dynamic Linear Rational Expectations Models," Journal of Economic Dynamics and Control, 2, 7-46.

[8] Hansen, Lars Peter (1982). "Large Sample Properties of Generalized Method of Moments Estimators," Econometrica, 50, 1029-54.

[9] Hausman, Jerry (1984). "Specification and Estimation of Simultaneous Equations Models," in Zvi Griliches and Michael Intriligator (eds.), Handbook of Econometrics, Amsterdam: North-Holland.

[10] Mankiw, N. Gregory and Ricardo Reis (2001). "Sticky Information Versus Sticky Prices: A Proposal to Replace the New Keynesian Phillips Curve," working paper, Harvard University.

[11] Newey, Whitney L. (1985). "Generalized Method of Moments Specification Testing," Journal of Econometrics, 29, 229-256. 
[12] Roberts, John M. (1995). "New Keynesian Economics and the Phillips Curve," Journal of Money, Credit, and Banking, 27, 975-984.

[13] Roberts, John M. (2001). "How Well Does the New-Keynesian Sticky-Price Model Fit the Data?" Federal Reserve Board, Finance and Economics Discussion Series, No. 2001-13.

[14] Sims, Christopher A. (1998). "Stickiness," Carnegie-Rochester Conference Series on Public Policy, 49, 317-356.

[15] Staiger, Douglas, James Stock, and Mark Watson (1997). "How Precise Are Estimates of the Natural Rate of Unemployment?" in Christina Romer and David Romer (eds.), Reducing Inflation, Chicago: University of Chicago Press.

[16] Taylor, John B. (1980). "Aggregate Dynamics and Staggered Contracts," Journal of Political Economy, 88, 1-23. 


\section{A Properties of IV Estimates Under Misspecification}

In this appendix, we demonstrate the properties of the GMM estimates of equation (4) and the Hansen test of overidentifying restrictions for the specific case in which the true model is

$$
\pi_{t}=\beta \pi_{t-1}+\lambda x_{t}+\mu z_{t}+u_{t}
$$

where $u_{t}$ is white noise, and $x$ and $z$ are characterized by first-order autoregressive processes:

$$
\begin{aligned}
& x_{t}=\rho_{x} x_{t-1}+\epsilon_{t}^{x}, \\
& z_{t}=\rho_{z} z_{t-1}+\epsilon_{t}^{z} .
\end{aligned}
$$

Under these conditions, the process for $\pi_{t+1}$ can be written as

$$
\begin{aligned}
\pi_{t+1} & =\beta \pi_{t}+\lambda x_{t+1}+\mu z_{t+1}+u_{t+1} \\
& =\beta\left(\beta \pi_{t-1}+\lambda x_{t}+\mu z_{t}+u_{t}\right)+\lambda \rho_{x} x_{t}+\mu \rho_{z} z_{t}+\lambda \epsilon_{t+1}^{x}+\mu \epsilon_{t+1}^{z}+u_{t+1} \\
& =\beta^{2} \pi_{t-1}+\lambda\left(\beta+\rho_{x}\right) x_{t}+\mu\left(\beta+\rho_{z}\right) z_{t}+\lambda \epsilon_{t+1}^{x}+\mu \epsilon_{t+1}^{z}+\beta u_{t}+u_{t+1} .
\end{aligned}
$$

This expresses $\pi_{t+1}$ in terms of the variables in the first-stage regression, and a set of stochastic processes that are orthogonal to each of them. Asymptotically, we can write the fitted value for this model as

$$
\hat{\pi}_{t+1}=\hat{\delta}_{1} \pi_{t-1}+\hat{\delta}_{2} x_{t}+\hat{\delta}_{3} z_{t}
$$

where

$$
\begin{aligned}
& \hat{\delta}_{1}=\beta^{2}, \\
& \hat{\delta}_{2}=\lambda\left(\beta+\rho_{x}\right), \\
& \hat{\delta}_{3}=\mu\left(\beta+\rho_{z}\right) .
\end{aligned}
$$

The second-stage regression can now be expressed as

$$
\begin{aligned}
\pi_{t} & =\hat{\omega}^{f}\left(\hat{\delta}_{1} \pi_{t-1}+\hat{\delta}_{2} x_{t}+\hat{\delta}_{3} y_{t}\right)+\hat{\omega}^{b} \pi_{t-1}+\hat{\gamma} x_{t}+v_{t} \\
& =\left(\hat{\omega}^{b}+\hat{\omega}^{f} \hat{\delta}_{1}\right) \pi_{t-1}+\left(\hat{\gamma}+\hat{\omega}^{f} \hat{\delta}_{2}\right) x_{t}+\hat{\omega}^{f} \hat{\delta}_{3} z_{t}+v_{t} \\
& =\left(\hat{\omega}^{b}+\hat{\omega}^{f} \beta^{2}\right) \pi_{t-1}+\left(\hat{\gamma}+\hat{\omega}^{f} \lambda\left(\beta+\rho_{x}\right)\right) x_{t}+\hat{\omega}^{f} \mu\left(\beta+\rho_{z}\right) z_{t}+v_{t} .
\end{aligned}
$$


So, we can write the probability limits of the parameter estimates as

$$
\begin{aligned}
\operatorname{plim}\left(\hat{\omega}^{b}+\hat{\omega}^{f} \beta^{2}\right) & =\beta, \\
\operatorname{plim}\left(\hat{\gamma}+\hat{\omega}^{f} \lambda\left(\beta+\rho_{x}\right)\right) & =\lambda, \\
\operatorname{plim} \hat{\omega}^{f} \mu\left(\beta+\rho_{z}\right) & =\mu,
\end{aligned}
$$

which implies that

$$
\begin{aligned}
\operatorname{plim} \hat{\omega}^{f} & =\frac{1}{\beta+\rho_{z}}, \\
\operatorname{plim} \hat{\omega}^{b} & =\frac{\beta \rho_{z}}{\beta+\rho_{z}}, \\
\operatorname{plim} \hat{\gamma} & =\lambda\left(\frac{\rho_{z}-\rho_{x}}{\beta+\rho_{z}}\right) .
\end{aligned}
$$

This gives equations (13), (14), and (15) in the text.

Finally, consider the properties of the Hansen test of the overidentifying restrictions. Drawing on an earlier result by Hausman (1984), Newey (1985) showed that for linear models this test statistic is equal to $(T-k) R^{2}$, where $T$ is the sample size, $k$ is the number of parameters being estimated, and the $R^{2}$ is from a regression of the model's errors on the instrument set. Under the null, this statistic is distributed as a $\chi^{2}$ with $m-k$ degrees of freedom, where $m$ denotes the number of variables in the instrument set.

For the case considered here, this test procedure involves regressing $\epsilon_{t}=\pi_{t}-$ $\widehat{\omega}^{f} \pi_{t+1}-\hat{\omega}^{b} \pi_{t-1}-\hat{\gamma} x_{t}$ on $x_{t}, z_{t}$, and $\pi_{t-1}$. Using the probability limits of the estimated parameters, we can calculate the probability limit for $\epsilon_{t}$ as follows:

$$
\begin{aligned}
\epsilon_{t}= & \pi_{t}-\frac{1}{\beta+\rho_{z}} \pi_{t+1}-\frac{\beta \rho_{z}}{\beta+\rho_{z}} \pi_{t-1}-\lambda\left(\frac{\rho_{z}-\rho_{x}}{\beta+\rho_{z}}\right) x_{t} \\
= & \pi_{t}-\frac{1}{\beta+\rho_{z}}\left[\beta^{2} \pi_{t-1}+\lambda\left(\beta+\rho_{x}\right) x_{t}+\mu\left(\beta+\rho_{z}\right) z_{t}+\lambda \epsilon_{t+1}^{x}+\mu \epsilon_{t+1}^{z}+\beta u_{t}+u_{t+1}\right] \\
& -\frac{\beta \rho_{z}}{\beta+\rho_{z}} \pi_{t-1}-\lambda\left(\frac{\rho_{z}-\rho_{x}}{\beta+\rho_{z}}\right) x_{t} \\
= & \pi_{t}-\beta \pi_{t-1}-\lambda x_{t}-\mu z_{t}+\frac{\lambda \epsilon_{t+1}^{x}+\mu \epsilon_{t+1}^{z}+\beta u_{t}+u_{t+1}}{\beta+\rho_{z}} \\
= & u_{t}+\frac{\lambda \epsilon_{t+1}^{x}+\mu \epsilon_{t+1}^{z}+\beta u_{t}+u_{t+1}}{\beta+\rho_{z}} \\
= & \frac{\lambda \epsilon_{t+1}^{x}+\mu \epsilon_{t+1}^{z}+\left(\beta^{2}+\beta+\rho_{z}\right) u_{t}+u_{t+1}}{\beta+\rho_{z}} .
\end{aligned}
$$


This series is uncorrelated with $z_{t}, x_{t}$, and $\pi_{t-1}$, so we should not expect to obtain a high $R^{2}$ from this regression. Indeed, asymptotically this $R^{2}$ should tend towards zero. As a result, the test will not be able to detect the presence of misspecification. The reason for this is that the role that $z_{t}$ plays in the regression is indirectly picked up through its effect on $\pi_{t+1}$. Thus, the misspecified regression has not "left out" the effect of $z_{t}$, thereby pushing it into the regression residual - which is what the Hansen test is attempting to detect. Rather, it has just incorrectly attributed the effect of $z_{t}$ to $\pi_{t+1}$. 
Table 1: "Hybrid" Inflation Equation-GMM Estimates

\begin{tabular}{lccc}
\hline \hline Driving variable $\left(x_{t}\right)$ & $\omega^{f}$ & $\omega^{b}$ & $\gamma$ \\
\hline A. NFB price inflation & & & \\
GDP gap & & & \\
& $0.777^{* *}$ & $0.218^{* *}$ & $-0.007^{*}$ \\
& $(0.044)$ & $(0.039)$ & $(0.003)$ \\
Labor's share & $0.748^{* *}$ & $0.237^{* *}$ & 0.002 \\
& $(0.039)$ & $(0.036)$ & $(0.004)$ \\
& & & \\
B. GDP price inflation & & & \\
& & & \\
GDP gap & $0.605^{* *}$ & $0.393^{* *}$ & -0.000 \\
& $(0.026)$ & $(0.027)$ & $(0.002)$ \\
Labor's share & $0.594^{* *}$ & $0.397^{* *}$ & 0.004 \\
& $(0.022)$ & $(0.023)$ & $(0.003)$ \\
& & & \\
\hline
\end{tabular}

Note: Standard errors in parentheses. ${ }^{* *} /{ }^{*} /{ }^{a}$ denotes significant at $1 / 5 / 10$ percent level, respectively. Estimation from 1960:Q1 to 1997:Q4. 
Table 2: Closed-Form Inflation Equations - IV Estimates $(\beta \equiv 0.95)$

\begin{tabular}{|c|c|c|}
\hline$\overline{\text { Driving variable }\left(x_{t}\right)}$ & $\gamma$ & $\overline{A A(1)}$ \\
\hline A. NFB price inflation & & \\
\hline GDP gap & $\begin{array}{c}-0.011^{* *} \\
(0.002)\end{array}$ & \\
\hline GDP gap & $\begin{array}{c}0.002^{* *} \\
(0.001)\end{array}$ & $\begin{array}{c}0.877^{* *} \\
(0.025)\end{array}$ \\
\hline Labor's share & $\begin{array}{c}0.012^{* *} \\
(0.003)\end{array}$ & \\
\hline Labor's share & $\begin{array}{c}0.005^{* *} \\
(0.001)\end{array}$ & $\begin{array}{c}0.795^{* *} \\
(0.027)\end{array}$ \\
\hline Memo: Own lags only & & $\begin{array}{c}0.892^{* *} \\
(0.043)\end{array}$ \\
\hline B. GDP price inflation & & \\
\hline GDP gap & $\begin{array}{c}-0.010^{* *} \\
(0.002)\end{array}$ & \\
\hline GDP gap & $\begin{array}{c}0.002^{* *} \\
(0.001)\end{array}$ & $\begin{array}{c}0.877^{* *} \\
(0.040)\end{array}$ \\
\hline Labor's share & $\begin{array}{c}0.011^{* *} \\
(0.003)\end{array}$ & \\
\hline Labor's share & $\begin{array}{c}0.004^{* *} \\
(0.001)\end{array}$ & $\begin{array}{c}0.806^{* *} \\
(0.032)\end{array}$ \\
\hline Memo: Own lags only & & $\begin{array}{c}0.918^{* *} \\
(0.038)\end{array}$ \\
\hline
\end{tabular}

Note: Standard errors in parentheses. ${ }^{* *} /{ }^{*} /{ }^{a}$ denotes significant at $1 / 5 / 10$ percent level, respectively. $A(1)$ is the sum of the coefficients on two lags of inflation. 
Table 3: First-Stage Regressions for Present-Value Terms $(K \equiv 12, \beta \equiv 0.95)$

\begin{tabular}{|c|c|c|c|c|c|c|}
\hline & \multicolumn{3}{|c|}{ NFB inflation } & \multicolumn{3}{|c|}{ GDP inflation } \\
\hline & \multicolumn{2}{|c|}{ Sum of coeffs. } & \multirow[b]{2}{*}{$\bar{R}^{2}$} & \multicolumn{2}{|c|}{ Sum of coeffs. } & \multirow[b]{2}{*}{$\bar{R}^{2}$} \\
\hline & $x$ lags & $\pi$ lags & & $x$ lags & $\pi$ lags & \\
\hline 1. $x_{t} \equiv G D P$ gap & & & & & & \\
\hline Full instrument set & $\begin{array}{c}5.88^{* *} \\
(0.72)\end{array}$ & $\begin{array}{c}-19.05^{* *} \\
(4.76)\end{array}$ & 0.57 & $\begin{array}{c}5.98^{* *} \\
(0.72)\end{array}$ & $\begin{array}{c}-21.71^{* *} \\
(5.96)\end{array}$ & 0.56 \\
\hline Full set less lagged $\pi_{t}$ & $\begin{array}{l}6.12^{* *} \\
(0.74)\end{array}$ & & 0.53 & $\begin{array}{c}6.12^{* *} \\
(0.74)\end{array}$ & & 0.53 \\
\hline Lagged $x_{t}$ and $\pi_{t}$ only & $\begin{array}{l}5.21^{* *} \\
(0.53)\end{array}$ & $\begin{array}{c}-11.18^{* *} \\
(2.30)\end{array}$ & 0.50 & $\begin{array}{l}5.28^{* *} \\
(0.54)\end{array}$ & $\begin{array}{c}-13.25^{* *} \\
(2.54)\end{array}$ & 0.50 \\
\hline Lagged $x_{t}$ only & $\begin{array}{l}4.14^{* *} \\
(0.52)\end{array}$ & & 0.41 & $\begin{array}{l}4.14^{* *} \\
(0.52)\end{array}$ & & 0.41 \\
\hline Lagged $\pi_{t}$ only & & $\begin{array}{c}-10.62^{* *} \\
(2.68)\end{array}$ & 0.08 & & $\begin{array}{c}-10.70^{* *} \\
(3.04)\end{array}$ & 0.07 \\
\hline 2. $x_{t} \equiv$ Labor's share & & & & & & \\
\hline Full instrument set & $\begin{array}{l}7.60^{* *} \\
(0.52)\end{array}$ & $\begin{array}{c}0.69 \\
(2.34)\end{array}$ & 0.79 & $\begin{array}{c}7.63^{* *} \\
(0.51)\end{array}$ & $\begin{array}{c}2.63 \\
(2.89)\end{array}$ & 0.79 \\
\hline Full set less lagged $\pi_{t}$ & $\begin{array}{l}7.42^{* *} \\
(0.50)\end{array}$ & & 0.79 & $\begin{array}{l}7.42^{* *} \\
(0.50)\end{array}$ & & 0.79 \\
\hline Lagged $x_{t}$ and $\pi_{t}$ only & $\begin{array}{l}5.37^{* *} \\
(0.62)\end{array}$ & $\begin{array}{l}4.47^{* *} \\
(1.54)\end{array}$ & 0.48 & $\begin{array}{c}5.11^{* *} \\
(0.61)\end{array}$ & $\begin{array}{c}6.54^{* *} \\
(1.72)\end{array}$ & 0.50 \\
\hline Lagged $x_{t}$ only & $\begin{array}{c}5.96^{* *} \\
(0.59)\end{array}$ & & 0.46 & $\begin{array}{c}5.96^{* *} \\
(0.59)\end{array}$ & & 0.46 \\
\hline Lagged $\pi_{t}$ only & & $\begin{array}{c}9.74^{* *} \\
(1.83)\end{array}$ & 0.15 & & $\begin{array}{c}12.67^{* *} \\
(1.96)\end{array}$ & 0.20 \\
\hline
\end{tabular}

Notes: Standard errors in parentheses. ${ }^{* *} /{ }^{*} /{ }^{a}$ denotes significant at $1 / 5 / 10$ percent level. 
Table 4: Closed-Form Inflation Equations-Hansen-Sargent Estimates $(\beta \equiv 0.95)$

\begin{tabular}{|c|c|c|c|}
\hline Driving variable $\left(x_{t}\right)$ & $\gamma$ & $A(1)$ & $\overline{\bar{R}^{2}}$ \\
\hline \multicolumn{4}{|l|}{ A. NFB price inflation } \\
\hline GDP gap & $\begin{array}{r}0.005^{a} \\
(0.003)\end{array}$ & & 0.01 \\
\hline GDP gap & $\begin{array}{c}0.005^{* *} \\
(0.001)\end{array}$ & $\begin{array}{c}0.893^{* *} \\
(0.043)\end{array}$ & 0.75 \\
\hline Labor's share & $\begin{array}{c}0.016^{* *} \\
(0.003)\end{array}$ & & 0.12 \\
\hline Labor's share & $\begin{array}{c}0.002 \\
(0.002)\end{array}$ & $\begin{array}{c}0.873^{* *} \\
(0.048)\end{array}$ & 0.73 \\
\hline B. GDP price inflatio & & & \\
\hline GDP gap & $\begin{array}{r}0.005^{*} \\
(0.002)\end{array}$ & & 0.03 \\
\hline GDP gap & $\begin{array}{c}0.003^{* *} \\
(0.001)\end{array}$ & $\begin{array}{c}0.911^{* *} \\
(0.035)\end{array}$ & 0.82 \\
\hline Labor's share & $\begin{array}{c}0.015^{* *} \\
(0.003)\end{array}$ & & 0.17 \\
\hline Labor's share & $\begin{array}{c}0.002 \\
(0.001)\end{array}$ & $\begin{array}{c}0.893^{* *} \\
(0.039)\end{array}$ & 0.82 \\
\hline
\end{tabular}

Notes: Standard errors in parentheses. ${ }^{* *} /{ }^{*} /{ }^{a}$ denotes significant at $1 / 5 / 10$ percent level, respectively. $A(1)$ is the sum of the coefficients on two lags of inflation. 
Table 5: Lagged Inflation Term: Closed-Form Models with Additional Correlates

\begin{tabular}{lcc}
\hline \hline & \multicolumn{2}{c}{$A(1)$} \\
\cline { 2 - 3 } Driving variable $\left(x_{t}\right)$ & no PDV & with $P D V$ \\
\hline \multirow{2}{*}{ A. NFB price inflation } & & \\
GDP gap & $0.699^{* *}$ & $0.672^{* *}$ \\
& $(0.073)$ & $(0.075)$ \\
Labor's share & $0.685^{* *}$ & $0.752^{* *}$ \\
& $(0.072)$ & $(0.046)$ \\
& & \\
B. GDP price inflation & & \\
GDP gap & & \\
& $0.630^{* *}$ & $0.607^{* *}$ \\
Labor's share & $(0.075)$ & $(0.097)$ \\
& $0.619^{* *}$ & $0.710^{* *}$ \\
& $(0.073)$ & $(0.047)$ \\
& & \\
\hline
\end{tabular}

Notes: Standard errors in parentheses. ${ }^{* *} /{ }^{*} /{ }^{a}$ denotes significant at $1 / 5 / 10$ percent level. 